\title{
Sensory Evaluation of Low-Carbon City Tourism by Gray Relational Analysis
}

\author{
Cheng Yueh-Te, Liang Ru-Qian*, Ho Meei-Chen and Wu Chao-Hsien \\ Guangxi University of Finance and Economics, School of Business Administration, Nanning City, Guangxi, China
}

\begin{abstract}
The promotion of low-carbon city tourism is an important measure to reduce carbon emissions in various regions and realize sustainability. This research explores tourists' sensory experience in the city's lowcarbon tourism economy, environment and society from urban low-carbon tourism and providing relevant units with a blueprint for urban low-carbon tourism planning. This research accompanies the empirical cases and introduces Gray Relational Analysis to overcome the difficulties in practice, sometimes due to cost and time constraints, that strategies must formulate with little information, little data, or uncertainty. The research results show that the top low-carbon tourism evaluations of Tainan's business districts by tourism experts are An-Ping Business District and Cheng- Kung University Business District. Relevant planners can refer to this ranking and weight to analyse sensory marketing opportunities to help create a more attractive low-carbon tourism city.
\end{abstract}

\section{Introduction}

The development of low-carbon city tourism is a meaningful way to realize the vision of sustainability. Cities account for about 3\% of the world's land area but account for more than $70 \%$ of global carbon emissions. Low-carbon cities' development is an essential step towards a sustainable vision $[1,2]$. For example, London and Rotterdam seek to reduce carbon emissions by $60 \%$ and $50 \%$ by 2025 , respectively $[3,4]$. A low-carbon city is a constraint on resources and energy by decision-makers from the perspective of achieving low-carbon. It is a complex dynamic system involving the economy, society, population, resources, environment, and other subsystems. The development of low-carbon cities must consider other subsystems to reduce carbon emissions [2, 5]. Many studies have pointed out that low-carbon tourism is one of the crucial subsystems and ways to develop low-carbon cities [6].

The United Nations World Tourism Organization (UNWTO) reported in January 2020 that: In 2019, international tourist arrivals worldwide reached 1.5 billion, and it predicted that the annual growth rate would continue to be $3 \%$ to $4 \%$ in the future[7], the tourism industry will become one of the important drivers of economic growth. Among them, the urban population accounts for more than $50 \%$ of the global population, and it estimated that it would account for two-thirds in 2030. The population of developing countries will double. Strengthening urban tourism has become the main strategic goal for developing the tourism industry in all world regions $[8,9]$. Urban tourism has become one of the main drivers of urban economic, cultural, and social development [10-12].
However, with the successful development of urban tourism, tourists' carbon emissions are also increasing. Achieving the sustainable vision of reducing carbon emissions makes it necessary to promote sustainable measures more suitable for urban resources.

Urban low-carbon tourism involves complex and multifaceted factors, which are different from other forms of tourism. Research points out that the promotion of lowcarbon tourism can start from economic, environmental, and social aspects [5]. The research pointed out that increasing investment in low-carbon infrastructure, promoting low-carbon materials and low-carbon labels, disseminating low-carbon concepts among stakeholders in the tourism industry, continuing low-carbon education for tourism practitioners, formulating and implementing lowcarbon development relevant policies and regulations, the active promotion of low-carbon technology, popularization of sustainable energy, etc. [5].

Tourists' diversified sensory impressions will affect tourists' willingness to travel to low-carbon cities. Tourist experience will have a long-term impact on loyalty to travel destinations, and good diversified sensory impressions will enhance tourists 'travel to travel destinations [13-15]. Studies have shown that the tourist experience is affected by the sensory dimension (sight, hearing, touch, taste and smell). The tourist experience is a multi-dimensional construct, and the sensory dimension is the most important key factor. The sensory experience of tourists refers to the experience gained by tourists through sensory systems such as sight, hearing, touch, taste and smell. The sensory system is part of the processing of sensory information in the nervous system of the nervous system. It is a channel for the external physical world and internal feeling. Tourists shape the

* Corresponding author: 496575274@qq.com 
sensory experience through interaction with the external environment (intentional or unintentional) [14]. For example, the smell of air can be smelled through the olfactory nervous system. Hear noise through the auditory nervous system; understand the image of local food through the taste nervous system; see the scenery through the visual nervous system and feel the warmth of the trees through the tactile nervous system. Research shows that tourists experience positive and negative destination images or sensory impressions formed by the sensory dimension, and the tourist experience has a significant effect on the destination loyalty of tourists. The human sensory dimension is a communication channel for exploring and understanding everything. Tourism experience refers to the process of stimulating the sensory dimension to form the image or sensory impression of the destination. Image is the subjective view of people; an abstract thinking of subjective values generated by people directly or indirectly receiving information about things. Destination image is the sum of ideas, beliefs and perceptions that people hold of places. The destination image is the overall perception of the tourist's belief image, impression image, idea image, and perception image of the tourist destination. Tourists will be transformed into more complicated images after receiving previous experience or external related information. For example, tourists may use local facilities and use sensory dimensions to leave the destination's low-carbon city image. The destination image and sensory impression may coexist, but they have different psychological mechanisms (Fig. 1) [15]. A tourist will evaluate according to the quality of the destination image or sensory impression, and then affect the satisfaction and loyalty of the tourist to the tourist destination, whether to consider revisiting or recommending Important factors for others.

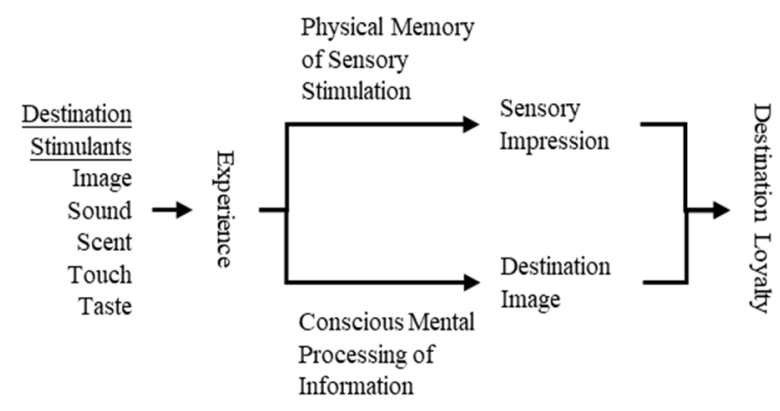

Fig1. Difference between sensory impression and destination image[15].

Synthesizing the above literatures, this research explores tourists' sensory experience in the city's lowcarbon tourism economy, low-carbon tourism environment, and low-carbon tourism society from urban low-carbon tourism and providing relevant units with a blueprint for urban low-carbon tourism planning. This research does the empirical cases accompany and introduces Gray Relational Analysis to overcome the difficulties in practice, sometimes due to cost and time constraints, that strategies must formulate with little information, little data or uncertainty.

\section{Methods}

According to the purpose of this research, the research framework of this research is (Fig. 2):

1. First, a focus group consisting of 14 tourism experts made a correlation score based on the 6 main business districts and low-carbon sensory experiences in Tainan. The higher the number, the higher the satisfaction of tourism experts with low-carbon tourism in the business district.

Tourist experience affects the loyalty of tourist destinations. The sensory dimension is the most important key factor affecting the low-carbon city tourist experience. Visitors shape the sensory experience through the interaction of the sensory dimension and the external environment. Therefore, a good external environment or destination image will enhance tourists' loyalty, which will trigger a revisit or a good reputation. Sensory marketing planners for travel destinations can increase the level of satisfaction and loyalty by understanding the extent to which tourists experience tourist destinations.

2. Calculate the average score of low-carbon tourism experts separately, and then normalize the data to calculate the gray correlation coefficient.

Grey relational analysis was proposed by Deng Julong in 1982. It is a measure to analyse the degree of correlation between discrete series [16]. Compared with the traditional factor analysis methods, a large amount of data is required, and the distribution pattern of the data must be a typical distribution before it can be calculated. Grey correlation analysis has the characteristics of not requiring a large amount of sample data and multi-factor analysis. In the case of less information, less data, and uncertainty, through the process of the reference sequence and the comparison sequence, the obtained data is analysed and quantified in a multidimensional perspective, which is different from other comparison methods without reference objects; because there is no reference Objects, thus ignoring the comparative environment, are prone to illusion and misunderstanding. This research is mainly to apply the grey relational analysis to overcome the predicament that the design criteria weights must be formulated under the environment of little information and uncertainty due to cost and time constraints.

3. Sort and compare the grey correlation coefficient. A higher score indicates that the business district has an advantage over other business districts, and a lower score indicates that the business district has a disadvantage compared to other business districts.

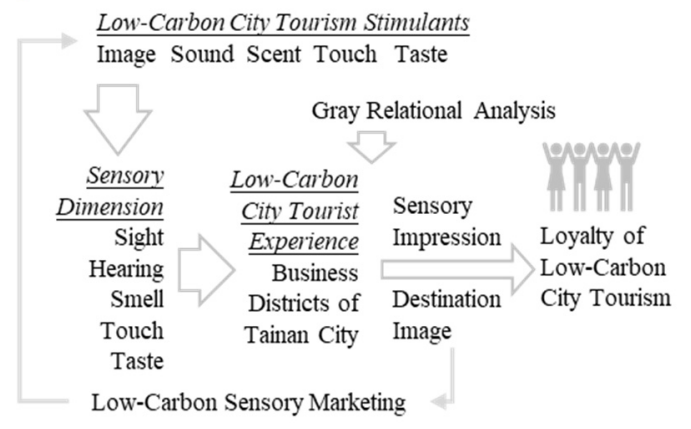

Fig2. Research framework. 


\section{Results and Discussion}

In this study, the results of the data were collated and then analysed by grey relational analysis. The business districts of Tainan City selected were Ping Business District, Confucius Temple Business District, Cheng Kung University, Zhong Zheng Business District, Guo Hua Business District and Hai An Business District. The sensory experience of image, sound, scent, touch, taste is the evaluation index (table 1).

Table1. Evaluation of Low-Carbon Tourists.

\begin{tabular}{cccccc}
\hline $\begin{array}{c}\text { Business } \\
\text { District }\end{array}$ & Image & Sound & Scent & Touch & Taste \\
\hline AP & 6.854 & 7.112 & 6.844 & 5.624 & 6.542 \\
CT & 6.648 & 6.035 & 6.325 & 6.042 & 6.327 \\
CK & 6.612 & 6.541 & 6.528 & 6.064 & 6.479 \\
ZZ & 5.564 & 6.632 & 5.694 & 5.238 & 5.634 \\
GH & 6.102 & 7.258 & 5.541 & 5.884 & 5.875 \\
HA & 6.054 & 6.751 & 5.667 & 5.648 & 5.961 \\
\hline
\end{tabular}

AP: An Ping Business District; CT: Confucius Temple Business District; CK: Cheng Kung University; ZZ: Zhong Zheng Business District; GH: Guo Hua Business District; HA: Hai An Business District.

Because the importance reference sequences of this study are each its maximum value, the local gray correlation is used as the calculation method. The analysis steps are as follows: Calculate Grey Relational Generation and Grey Relational Grade: As the relationship between the 6 major business districts and the tourist experience matrix in Tainan City, all the data conversions belong to the larger the better. Table 2 shows the results of calculating gray-scale correlation generation and data normalization.

Table2. Gray Correlation Generation and Data Normalization.

\begin{tabular}{cccccc}
\hline $\begin{array}{c}\text { Business } \\
\text { District }\end{array}$ & Image & Sound & Scent & Touch & Taste \\
\hline AP & 1.000 & 0.881 & 1.000 & 0.467 & 1.000 \\
CT & 0.840 & 0.000 & 0.602 & 0.973 & 0.763 \\
CK & 0.812 & 0.414 & 0.757 & 1.000 & 0.931 \\
ZZ & 0.000 & 0.488 & 0.117 & 0.000 & 0.000 \\
GH & 0.417 & 1.000 & 0.000 & 0.782 & 0.265 \\
HA & 0.380 & 0.585 & 0.097 & 0.496 & 0.360 \\
\hline
\end{tabular}

AP: An Ping Business District; CT: Confucius Temple Business District; CK. Cheng Kung University; ZZ: Zhong Zheng Business District; GH: Guo Hua Business District; HA: Hai An Business District.

Calculate the local gray correlation: The results are shown in table 3. In order to increase the discrepancy of the results in this study, the identification coefficient was taken as 1 and substituted into the gray correlation coefficient. The calculation results are shown in table 4 .

Table3. Calculate the Local Gray Correlation.

\begin{tabular}{cccccc}
\hline $\begin{array}{c}\text { Business } \\
\text { District }\end{array}$ & Image & Sound & Scent & Touch & Taste \\
\hline AP & 0.000 & 0.119 & 0.000 & 0.533 & 0.000 \\
CT & 0.160 & 1.000 & 0.398 & 0.027 & 0.237 \\
CK & 0.188 & 0.586 & 0.243 & 0.000 & 0.069 \\
ZZ & 1.000 & 0.512 & 0.883 & 1.000 & 1.000 \\
GH & 0.583 & 0.000 & 1.000 & 0.218 & 0.735 \\
HA & 0.620 & 0.415 & 0.903 & 0.504 & 0.640 \\
\hline
\end{tabular}

AP: An Ping Business District; CT: Confucius Temple Business District; CK: Cheng Kung University; ZZ: Zhong Zheng Business District; GH: Guo Hua Business District; HA: Hai An Business District.

Table4. Gray Correlation Coefficient.

\begin{tabular}{cccccc}
\hline $\begin{array}{c}\text { Business } \\
\text { District }\end{array}$ & Image & Sound & Scent & Touch & Taste \\
\hline AP & 1.000 & 0.893 & 1.000 & 0.652 & 1.000 \\
CT & 0.862 & 0.500 & 0.715 & 0.974 & 0.809 \\
CK & 0.842 & 0.630 & 0.805 & 1.000 & 0.935 \\
ZZ & 0.500 & 0.661 & 0.531 & 0.500 & 0.500 \\
GH & 0.632 & 1.000 & 0.500 & 0.821 & 0.577 \\
HA & 0.617 & 0.707 & 0.525 & 0.665 & 0.610 \\
\hline
\end{tabular}

AP: An Ping Business District; CT: Confucius Temple Business District; CK: Cheng Kung University; ZZ: Zhong Zheng Business District; GH: Guo Hua Business District; HA: Hai An Business District.

Calculate the gray correlation: After the gray correlation coefficient is obtained, the gray correlation value can be calculated. The weight is calculated by substituting the value obtained from the quality planning weight of the cover design requirements. In order to make the value between 0 and 1 , the weights are normalized. The calculation result is shown in table 5 , and then the sum is the gray correlation value.

Table5. Calculate the Degree of Gray Correlation.

\begin{tabular}{cccccc}
\hline $\begin{array}{c}\text { Business } \\
\text { District }\end{array}$ & Image & Sound & Scent & Touch & Taste \\
\hline AP & 0.145 & 0.132 & 0.143 & 0.159 & 0.159 \\
CT & 0.125 & 0.074 & 0.103 & 0.237 & 0.128 \\
CK & 0.122 & 0.093 & 0.115 & 0.244 & 0.148 \\
ZZ & 0.073 & 0.098 & 0.076 & 0.122 & 0.079 \\
GH & 0.092 & 0.148 & 0.072 & 0.200 & 0.092 \\
HA & 0.090 & 0.105 & 0.075 & 0.162 & 0.097 \\
\hline
\end{tabular}

AP: An Ping Business District; CT: Confucius Temple Business District; CK: Cheng Kung University; ZZ: Zhong Zheng Business District; GH: Guo Hua Business District; HA: Hai An Business District.

After the gray correlation coefficient is obtained, the gray correlation degree can be calculated. If weights are considered and each weight value is different, the calculation formula is as follows. Finally calculate Grey relational ordinal (table 6). Low-carbon tourism related units can refer to grey correlation value and rank ranking to plan their strategies. The results of the study show that the quality of low-carbon tourism in Tainan is ranked: An Ping Business District (0.738), Cheng Kung University Business District (0.723), Confucius Temple Business District (0.667), Guo Hua Business District (0.603), Hai An Business District (0.528) and Zhong Zheng Business District (0.448). Low-carbon city tourism planners can refer to this ranking or weight to plan more attractive cities.

Table6. Ordinal Analysis.

\begin{tabular}{ccc}
\hline Business District & Value & Order \\
\hline AP & 0.738 & 1 \\
CT & 0.667 & 3 \\
CK & 0.723 & 2 \\
ZZ & 0.448 & 6 \\
GH & 0.603 & 4 \\
HA & 0.528 & 5 \\
\hline
\end{tabular}

AP: An Ping Business District; CT: Confucius Temple Business District; CK: Cheng Kung University; ZZ: 
Zhong Zheng Business District; GH: Guo Hua Business District; HA: Hai An Business District.

\section{Conclusions}

Many studies have pointed out that low-carbon tourism is one of the ways to develop low-carbon cities. This research explores tourists' sensory experience in the city's low-carbon tourism economy, environment and society from urban low-carbon tourism and providing relevant units with a blueprint for urban low-carbon tourism planning. This research accompanies the empirical cases and introduces Gray Relational Analysis to overcome the difficulties in practice, sometimes due to cost and time constraints, that strategies must formulate with little information, little data, or uncertainty. The research results show that the top low-carbon tourism evaluations of Tainan's business districts by tourism experts are An Ping Business District, Cheng Kung University Business District, Confucius Temple Business District, Guo Hua Business District, Hai An Business District and Zhong Zheng Business District. Low-carbon tourism planners can refer to this ranking and weight to analyse sensory marketing opportunities to help create a more attractive city.

\section{References}

1. Z. Wang, X. Dou, P. Wu, S. Liang, B. Cai, L. Cao, L. Pang, X. Bo, and L. Wei, Who is a good neighbor? Analysis of frontrunner cities with comparative advantages in low-carbon development, Journal of Environmental Management, 269, 110804. (2020)

2. Y. Wang, X. Fang, S. Yin, and W. Chen, Low-carbon development quality of cities in China: Evaluation and obstacle analysis, Sustainable Cities and Society, 64, 102553. (2021)

3. S. Tan, J. Yang, J. Yan, C. Lee, H. Hashim, and B. Chen, A holistic low carbon city indicator framework for sustainable development, Applied Energy, 185, 1919-1930. (2017)

4. H. Azizalrahman, and V. Hasyimi, Towards a generic multi-criteria evaluation model for low carbon cities, Sustainable Cities and Society, 39, 275-282. (2018)

5. J. Zhang, and Y. Zhang, Assessing the low-carbon tourism in the tourism-based urban destinations, Journal of Cleaner Production, 276, 124303. (2020)

6. J. Pongthanaisawan, W. Wangjiraniran, K. Chuenwong, and L. Pimonsree, Scenario Planning for Low Carbon Tourism City: A Case Study of Nan, Energy Procedia, 152, 715-724. (2018)

7. UNWTO, UNWTO World Tourism Barometer, UNWTO World Tourism Barometer and Statistical Annex, 17, 1. (2019)

8. M. Boivin, and G. A. Tanguay, Analysis of the determinants of urban tourism attractiveness: The case of Québec City and Bordeaux, Journal of Destination Marketing \& Management, 11, 67-79. (2019)

9. U. Gretzel, H. Werthner, C. Koo, and C. Lamsfus, Conceptual foundations for understanding smart tourism ecosystems, Computers in Human Behavior, 50, 558-563. (2015)

10. W. Zheng, H. Ji, C. Lin, W. Wang, and B. Yu, Using a heuristic approach to design personalized urban tourism itineraries with hotel selection, Tourism Management, 76, 103956. (2020)

11. S. Carlisle, A. Johansen, and M. Kunc, Strategic foresight for (coastal) urban tourism market complexity: The case of Bournemouth, Tourism Management, 54, 81-95. (2016)

12. D. Edwards, T. Griffin, and B. Hayllar, Urban Tourism Research: Developing an Agenda, Annals of Tourism Research, 35, 4, 1032-1052. (2008)

13. D. Agapito, P. Pinto, and J. Mendes, Tourists' memories, sensory impressions and loyalty: In loco and post-visit study in Southwest Portugal, Tourism Management, 58, 108-118. (2017)

14. F. Mehraliyev, A. P. Kirilenko, and Y. Choi, From measurement scale to sentiment scale: Examining the effect of sensory experiences on online review rating behavior, Tourism Management, 79, 104096. (2020)

15. X. Lv, C. Li, and S. McCabe, Expanding theory of tourists' destination loyalty: The role of sensory impressions, Tourism Management, 77, 104026. (2020)

16. D. Ju-Long, Control problems of grey systems, Systems \& Control Letters, 1, 5, 288-294. (1982) 